\title{
Heavy Oil Biodegradation by Mixed Bacterial Consortium of Biosurfactant-Producing and Heavy Oil-Degrading Bacteria
}

\author{
Xiaoli Dai ${ }^{1 *}$, Jing $\mathbf{L v}^{2}$, Shaohui Guo², Wenxia Wei ${ }^{1}$ \\ ${ }^{1}$ Beijing Key Laboratory of Remediation of Industrial Pollution Sites, Environmental Protection \\ Research Institute of Light Industry, Beijing 10089, China \\ ${ }^{2}$ China University of Petroleum, Beijing 102249, China
}

Received: 7 February 2020

Accepted: 18 April 2020

\begin{abstract}
Environmental contamination from heavy oil is a worldwide problem. In this study, a heavy oil degrading bacterial consortium DL-1314 composed of Bacillus sp. DL-13, Brevibacillus sp. DL-1 and Acinetobacter sp. DL-34 was constructed. The constituents were all biosurfactant-producing bacteria and heavy oil-degrading bacteria. Bench-scale experiments were used to investigate the performance of the bacterial consortium in degrading heavy oil. The bacterial consortium could quickly start up the heavy oil biodegradation and degrade $60.75 \%$ of heavy oil in 8 days. Gas chromatography-mass spectrometry (GC-MS) analysis evidenced that the bacterial consortium could degrade $66.32 \%$ of saturated hydrocarbons and $63.16 \%$ of aromatic hydrocarbons, especially $\mathrm{C} 15-\mathrm{C} 35 \mathrm{n}$-alkanes and 2ring-5-ring PAHs. Analysis of the dynamic changes in the consortium DL-1314 revealed that Bacillus sp. DL-13 played a major role in the formation of surfactants in the early stage of biodegradation, Brevibacillus sp. DL-1 degraded light hydrocarbons in heavy oil, and Bacillus sp. DL-13 and Acinetobacter sp. DL-34 degraded bio-refractory hydrocarbons in heavy oil by synergistic metabolism. In-depth characterization composition of the heavy oil and the microbial consortium revealed chemical and degradation diversity, providing a more comprehensive and accurate understanding of the biodegradation process.
\end{abstract}

Keywords: heavy oil contamination, bacterial consortium, biosurfactant-producing bacteria, heavy oil-degrading bacteria, saturated hydrocarbons, aromatic hydrocarbons

\section{Introduction}

Heavy oil has been widely used to meet the escalating energy demand all over the world due to the decrease in conventional oil and gas resources. Compared

*e-mail: daixiaoli@163.com with conventional crude oil, heavy oil contains more refractory resins, asphaltenes, polycyclic aromatic hydrocarbons (PAHs), heterocyclic compounds, and heavy metals $[1,2]$. Many of these components are biorefractory and toxic, therefore, heavy oil can cause more serious and lasting damage to the biological environment $[3,4]$. Thus, an efficient remediation technology for heavy oil contamination is urgently needed. 
Microbial degradation is the fundamental way to completely remove heavy oil from the environment [5-7]. However, the indigenous microbial community might not display the appropriate metabolic potential for heavy oil degradation due to the limitation in the physical properties of heavy oil $[8,9]$ and the longer domestication time, slower growth rate and lower metabolic activity of the indigenous microorganisms. In such cases, the solution for successful bioremediation might be the inoculation of the contaminated sites with efficient heavy oil-degrading microorganisms [10-13]. In addition, heavy oil has a very complicated composition [14], and its biodegradation usually requires a diverse population possessing broad metabolic mechanism [15]. The literature provides increasing evidence that the multimicrobe mixed systems (such as a constructed bacterial consortium) with broader suites of enzymes are more effective than single strain [16]. This motivated us to construct a bacterial consortium with the ability to synergistically degrade heavy oil.

Previous studies on heavy oil degradation using a microbial consortium usually considered bulk parameters, such as heavy oil degradation efficiency and microbial cell number [17-19]. Relatively few studies have investigated the changes in the composition of heavy oil and microbial consortium during the oil degradation. In-depth characterization of the composition of heavy oil and microbial consortium would undoubtedly reveal previously unrecognizable levels of chemical diversity and degradation diversity, thus providing a more comprehensive and accurate understanding of the biodegradation process.

In this study, a heavy oil- degrading bacterial consortium DL-1314 was constructed using separated heavy oil-degrading strains of Brevibacillus sp. DL-1, Bacillus sp. DL-13 and Acinetobacter sp. DL-34. The heavy oil degradation efficiency and microbial growth were monitored for biodegradation. Gas chromatographmass spectrometer (GC-MS) and dilution spread plate method were used to characterize changes in the composition of the heavy oil and the microbial consortium.

\section{Materials and Methods}

\section{Heavy Oil Composition}

The experimental oil was Venezuelan extra-heavy crude oil with the addition of diluents, containing $35.33 \%$ saturated hydrocarbons, $34.11 \%$ aromatic hydrocarbons, $\quad 19.87 \%$ asphaltenes and $12.27 \%$ resins. It was sourced from the "PetroChina Liaohe Petrochemical Company" in North China.

\section{Heavy Oil-Degrading Bacteria}

The bacteria used in this study were previously isolated from heavy oil-contaminated soil. The physiological, biochemical and degradation properties of the bacteria are presented in Table S1, Table S2, and

Table S1. Morphologhical and physiological properties of strain DL-1, DL-13 and DL-34.

\begin{tabular}{|c|c|c|c|}
\hline Characteristic & DL-1 & DL-13 & DL-34 \\
\hline Colony morphology & Milky white, Dry, Round & White, Wet, Round & Light yellow, Wet, Round \\
\hline Bacterial morphology & Short rod & Short rod & Short rod \\
\hline Gram staining & + & + & + \\
\hline Starch hydrolysis & + & - & + \\
\hline Oil hydrolysis & + & + & + \\
\hline Gelatin hydrolysis & + & - & + \\
\hline $\begin{array}{c}\text { Acid production from: } \\
\text { d-Glucose }\end{array}$ & + & + & + \\
\hline $\begin{array}{c}\text { Gas production from: } \\
\text { d-Glucose }\end{array}$ & + & + & + \\
\hline $\begin{array}{c}\text { Lactose hydrolysis } \\
\text { Acid production from: } \\
\text { sucrose }\end{array}$ & + & + & - \\
\hline $\begin{array}{c}\text { Gas production from: } \\
\text { sucrose }\end{array}$ & + & + & + \\
\hline Indole production & + & + & + \\
\hline $\begin{array}{l}\text { Methyl red } \\
\text { Citrate utilization test }\end{array}$ & + & + & + \\
\hline
\end{tabular}


Table S2. Characteristics and heavy degradation efficiency of strains.

\begin{tabular}{|c|c|c|c|c|}
\hline \multicolumn{2}{|l|}{ Characteristics } & DL-1 & DL-13 & DL-34 \\
\hline \multicolumn{2}{|l|}{ Heavy degradation efficiency } & $30.25 \%$ & $23.69 \%$ & $7.92 \%$ \\
\hline \multirow{4}{*}{$\begin{array}{c}\text { n-alkanes utilization } \\
\left(\text { ““++” } 0.3<\mathrm{OD} 600 \text {, “+” } 0.1<\mathrm{OD}_{600}<0.3 \text {,“-”OD600<0.1) }\right.\end{array}$} & $\mathrm{C} 11$ & + & + & + \\
\hline & $\mathrm{C} 16$ & ++ & ++ & + \\
\hline & $\mathrm{C} 24$ & ++ & ++ & + \\
\hline & $\mathrm{C} 36$ & ++ & + & + \\
\hline \multirow{7}{*}{$\begin{array}{c}\text { PAHs utilization } \\
(\text { (“++" } 0.3<\text { OD600, “+” } 0.1<\text { OD600<0.3,“-"OD600<0.1) }\end{array}$} & Naphthalene & + & + & + \\
\hline & Phenanthrene & + & ++ & + \\
\hline & Pyrene & ++ & ++ & + \\
\hline & Anthracene & ++ & ++ & + \\
\hline & Fluoranthene & ++ & ++ & + \\
\hline & Carbazole & ++ & ++ & + \\
\hline & Thiophene & ++ & ++ & + \\
\hline $\begin{array}{c}\text { Biosurfactant production capacity(“+++” strong, } \\
\text { "+"” low, “-”No) }\end{array}$ & & + & ++ & + \\
\hline
\end{tabular}

Fig. S1. Considering the significant differences in unit among the three bacteria, the consortium comprising three strains can be analyzed using the dilution spread plate method.

\section{Culture Medium}

The Luria Bertani (LB) medium contained $10 \mathrm{~g} / \mathrm{L}$ peptone, $10 \mathrm{~g} / \mathrm{L}$ beef extract and $10 \mathrm{~g} / \mathrm{L} \mathrm{NaCl}$. The medium was adjusted to $\mathrm{pH} 7.0$ and sterilized by autoclaving at $121^{\circ} \mathrm{C}$ for $30 \mathrm{~min}$ before use. Solid LB medium was prepared by adding $20 \mathrm{~g}$ agar into $1 \mathrm{~L} \mathrm{LB}$.

The mineral salt medium (MSM) contained $5 \mathrm{~g} / \mathrm{L}$ $\left(\mathrm{NH}_{4}\right)_{2} \mathrm{SO}_{4}, 3 \mathrm{~g} / \mathrm{L} \quad \mathrm{KH}_{2} \mathrm{PO}_{4}, 2 \mathrm{~g} / \mathrm{L} \quad \mathrm{Na}_{2} \mathrm{HPO}_{4} \cdot 2 \mathrm{H}_{2} \mathrm{O}$, $0.7 \mathrm{~g} / \mathrm{L} \mathrm{MgSO}_{4} \cdot 7 \mathrm{H}_{2} \mathrm{O}$ and $1 \mathrm{~mL}$ of trace element solution. The medium was adjusted to $\mathrm{pH} 7.0$ and sterilized by autoclaving at $121^{\circ} \mathrm{C}$ for $30 \mathrm{~min}$ before use. Solid MSM medium was prepared by adding $20 \mathrm{~g}$ agar into $1 \mathrm{~L}$ MSM.

\section{Heavy Oil-Degrading Consortium Construction}

Bacterial strains with broad degradation characteristics and biosurfactant production abilities (Table S1 and Table S2) were selected to construct a mixed bacterial consortium. The bacterial strain was separately incubated in a rotatory shaker $(160 \mathrm{r} / \mathrm{min})$ under aerobic conditions at $30^{\circ} \mathrm{C}$ for $24 \mathrm{~h}$. Cells in the LB medium were harvested by centrifugation at $5000 \mathrm{r} / \mathrm{min}$ for $10 \mathrm{~min}$ and washed three times, and the $\mathrm{OD}_{600}$ was adjusted to 0.8 with distilled saline solution. The composition of the bacterial consortium was optimized according to the design of combination experiments (Table 1). According to the design in Table 1, the different mixed bacterial consortia were inoculated into $30 \mathrm{~mL}$ MSM media with $0.01 \mathrm{~g}$ heavy oil. The contents of the vials were incubated in a rotatory shaker $(160 \mathrm{r} / \mathrm{min})$ under aerobic conditions at $30^{\circ} \mathrm{C}$ for 14 days. All of the experiments were
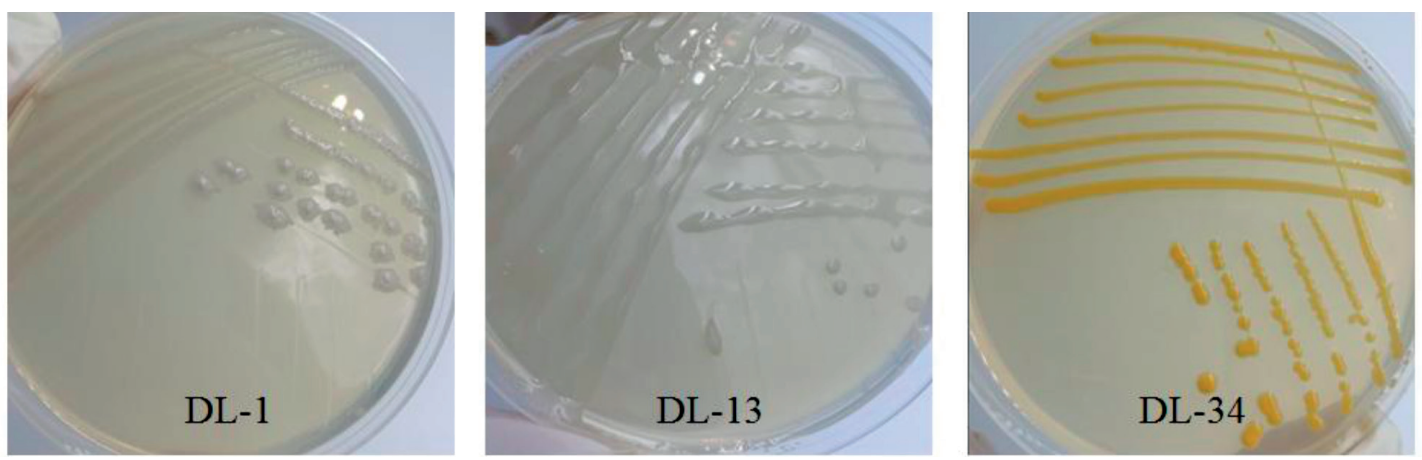

Fig. S1. Colony morphology of bacteria DL-1, DL-13 and DL-34. 
Table 1. Experimental design and results of strain combinations.

\begin{tabular}{|c|c|c|c|c|}
\hline Consortium & DL-13 $(\mathrm{mL})$ & DL-1 $(\mathrm{mL})$ & DL-34 $(\mathrm{mL})$ & Heavy oil degradation efficiency $(\%)$ \\
\hline DL-131 & 2 & 2 & 0 & 40.93 \\
\hline DL-134 & 0 & 2 & 2 & 20.70 \\
\hline DL-1334 & 2 & 0 & 2 & 40.52 \\
\hline DL-1314 & 2 & 2 & 2 & 60.20 \\
\hline
\end{tabular}

performed in triplicate. The consortium was constructed by comparing the heavy oil degradation efficiencies in the respective experiment designs.

\section{Heavy Oil Degradation Efficiency}

The optimized bacterial consortium was inoculated into $30 \mathrm{~mL}$ MSM medium with $0.01 \mathrm{~g}$ heavy crude oil. The contents of the vials were incubated in a rotatory shaker $(160 \mathrm{r} / \mathrm{min})$ under aerobic conditions at $30^{\circ} \mathrm{C}$ for 14 days. The residual heavy oil in each vial was extracted with $40 \mathrm{~mL} \mathrm{CCl}_{4}$ at time intervals of 1, 2, 4, $6,8,10,12,14$ and 16 days, and the heavy oil in the extract was measured using an infrared oil content analyzer (OIL-460, China Invent Instrument Tech. Ltd., China) according to the national standard method in China [20]. The heavy oil degradation efficiency was calculated using the following Equation (1):

$$
\text { Heavy oil degradation efficiency }(\%)=\frac{\mathcal{C}_{0}-\mathcal{C}_{t}}{\mathcal{C}_{0}} \times 100
$$

...where $C_{0}$ is the heavy oil initial concentration, and $C_{\mathrm{t}}$ is the heavy oil concentration after $t$ days of incubation.

\section{Heavy Oil Degradation Kinetics of Bacterial Consortium}

The microbial degradation of heavy oil is usually expressed by first-order kinetics [21,22] as given in Equation (2):

$$
L n_{C t}=-k t+b
$$

where $C_{\mathrm{t}}$ is the heavy oil concentration after $\mathrm{t}$ days of incubation, $\mathrm{k}$ is the biodegradation rate constant $\left(\right.$ day $\left.^{-1}\right)$, $\mathrm{t}$ is the time (day), and $\mathrm{b}$ is the fitting constant.

\section{GC-MS Analysis of Saturated and Aromatic Hydrocarbons}

Saturated hydrocarbons and aromatic hydrocarbons were separated by column chromatography. The residual heavy oil was dissolved in n-pentane to separate insoluble asphaltenes and further fractionated using activated alumina column chromatography. The saturated hydrocarbons were eluted with petroleum ether, and afterward, the aromatic hydrocarbons were eluted with toluene. The saturated and aromatic hydrocarbons eluents were adjusted separately to a volume of $2 \mathrm{~mL}$, spiked with a known amount of deuterated tetradecane $\left(\mathrm{n}-\mathrm{C}_{24} \mathrm{D}_{50}\right)$ and deuterated dibenzothiophene $\left(\mathrm{DBT}-\mathrm{D}_{8}\right)$ as an internal standard, and then analyzed using a GC-MS machine (Agilent 7890A/5975C, Agilent Technologies Inc., Santa Clara, CA, USA) equipped with an HP-5MS fused-silica capillary column. Details on the GC-MS operational program are given in Cai's work [14].

\section{Microbial Cell Number and Dynamic Changes of Bacterial Consortium}

The microbial cell number and dynamic changes of bacterial consortium were measured using the dilution spread plate method. For this measurement, $1 \mathrm{~mL}$ culture medium was suspended with $9 \mathrm{~mL}$ of $0.9 \%(\mathrm{w} / \mathrm{w}) \mathrm{NaCl}$. The suspension was serially diluted $\left(10^{-1}-10^{-8}\right)$. Then, the $10^{-3}, 10^{-4}$ and $10^{-5}$ dilutions were spread onto sterile LB agar plates. The plates were incubated at $30^{\circ} \mathrm{C}$ for 2 days prior to the counting of the colony forming units per $\mathrm{mL}(\mathrm{CFU} / \mathrm{mL})$. Three replicates were made at each dilution.

\section{Results and Discussion}

\section{Heavy Oil-Degrading Bacterial Consortium Construction}

Three bacterial strains with broader degradation substrate and biosurfactant production abilities were selected to form a bacterial consortium, including Brevibacillus sp. DL-1, Bacillus sp. DL-13, and Acinetobacter sp. DL-34. To achieve higher efficiency and broader spectrum in degrading complex petroleum hydrocarbon compounds, such as heavy oil, different mixed bacterial consortia were constructed (Table 1). As shown in Table 1, the heavy oil degradation efficiencies of the mixed bacterial consortia DL131, DL134, DL1334, and DL1314 were 40.93\%, 20.70\%, $40.52 \%$ and $60.20 \%$, respectively. This suggests that the bacterial consortium DL1314, which comprised strains of Brevibacillus sp. DL-1, Bacillus sp. DL-13 and Acinetobacter sp. DL-34, had the best performance 

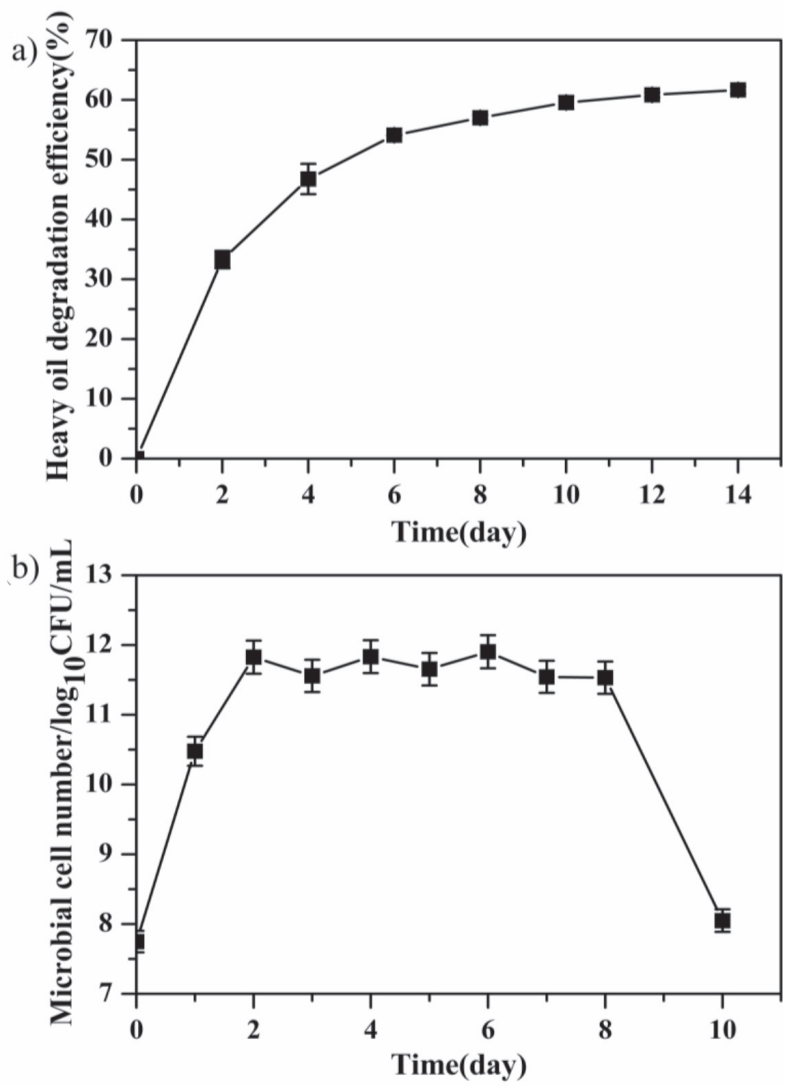

Fig. 1. Heavy oil degradation efficiency a) and microbial cell number b) of consortium DL-1314.

in heavy oil degradation. Furthermore, it can also be inferred that the strains of Bacillus sp. DL-13 may play a very important role in improving the heavy oil degradation efficiency.

\section{Changes in Heavy Oil Degradation Efficiency and Microbial Cell Number}

After 14 days of incubation (on day 14), the heavy oil degradation efficiency of the consortium DL-1314

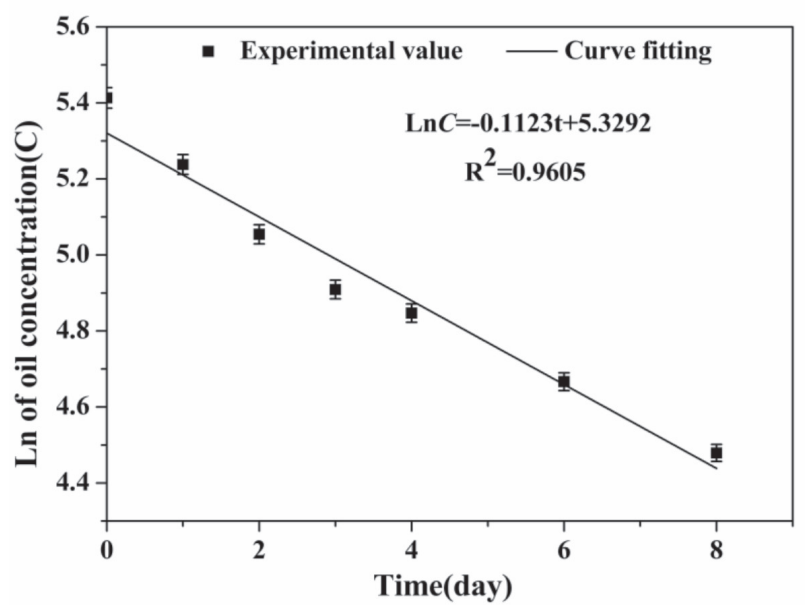

Fig. 2. Heavy oil degradation kinetics of consortium DL-1314. was $60.75 \%$ (Fig 1a), which was significantly higher than those of single strains $(30.25 \%, 23.69 \%$, and $7.92 \%)$. Fig. 1a) also showed that the heavy oil degradation efficiency rapidly increased within 2 days and the maximum degradation efficiency was reached on day 8. After 8 days, the heavy oil degradation efficiency did not change substantially with time. This is due to the inhibition in the growth and metabolic activity of the microorganisms, caused by the decrease in the degradable components of the heavy oil and the increase in toxic metabolites [17].

The microbial cell number rapidly increased to the maximum of $11.83 \log _{10} \mathrm{CFU} / \mathrm{mL}$ on day 2 when the heavy oil was used as carbon source for the growth of the consortium DL-1314 (Fig. 1b). After 8
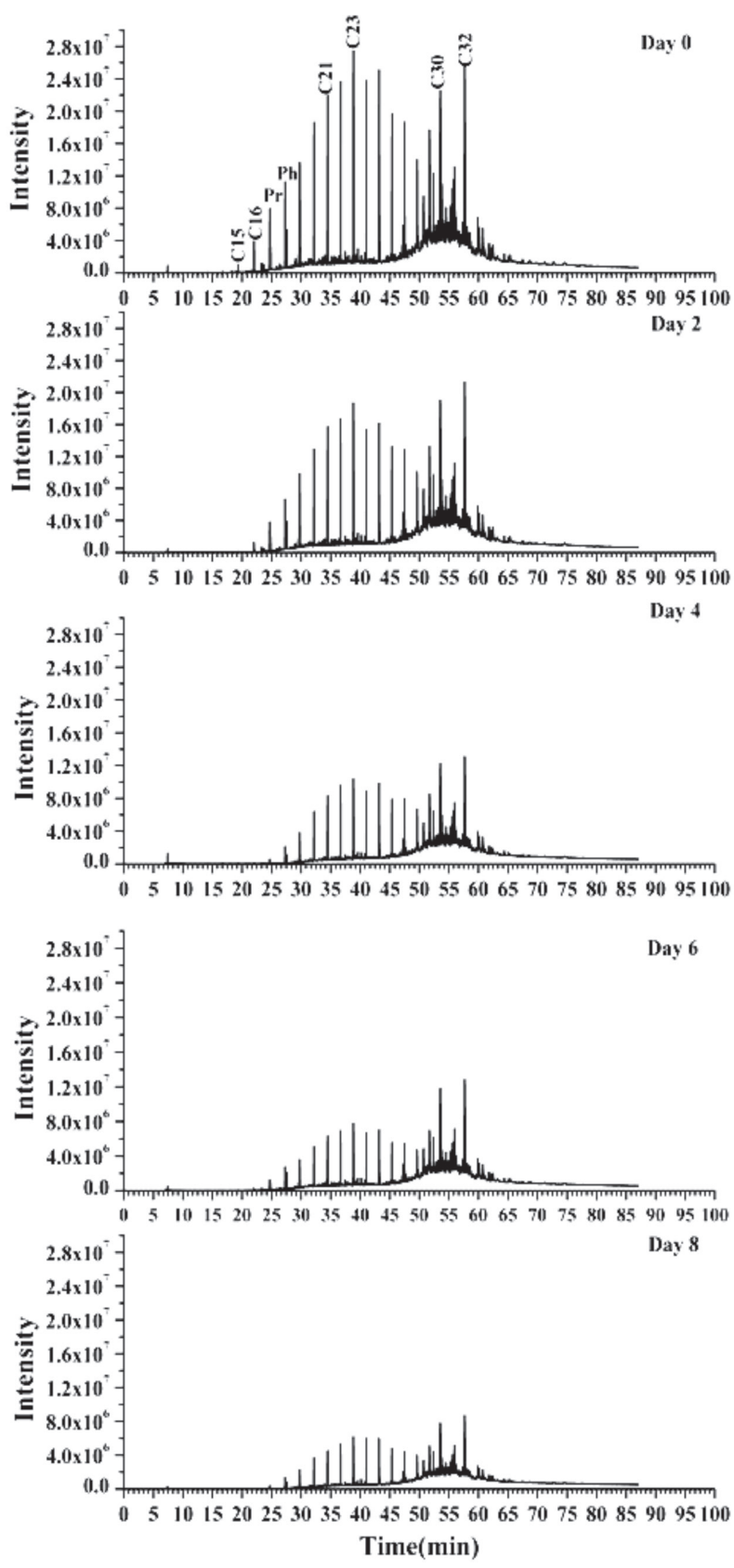

Fig. S2. Total ion chromatography of saturated hydrocarbons. 


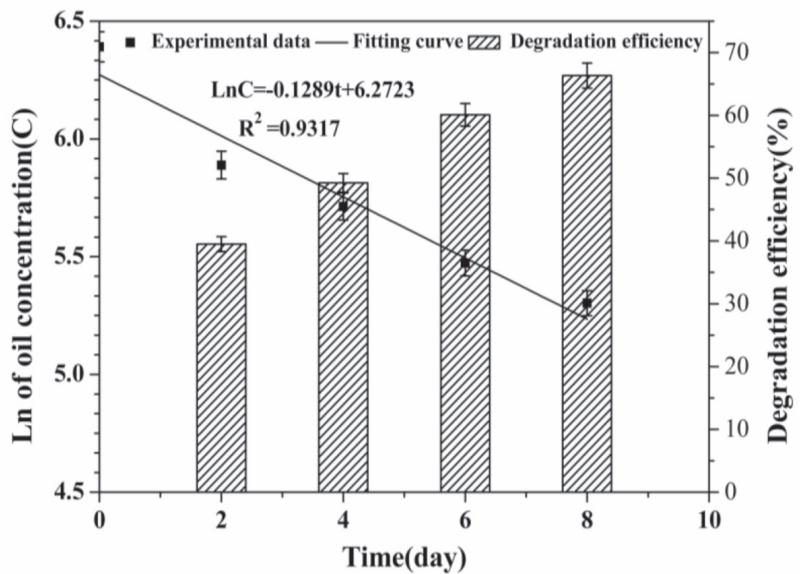

Fig. 3. Degradation efficiency and degradation kinetics of saturated hydrocarbons.

days, the biodegradation rate gradually declined with time.

The heavy oil degradation kinetics of consortium DL-1314 is presented in Fig. 2. The heavy oil degradation process of consortium DL-1314 accords with the first-order reaction equation $\left(\mathrm{R}^{2}=0.9605\right.$, $\mathrm{LnC}=-0.1123 \mathrm{t}+5.3292)$, and the reaction rate constant is $0.1123 \mathrm{~d}^{-1}$, which is significantly higher than those of previous studies $[13,23]$, suggesting that the consortium DL-1314 can rapidly start up the heavy oil degradation and has a high activity of heavy oil degradation.

\section{Biodegradation of Saturated Hydrocarbons of Heavy Oil}

The chemical composition of the saturated hydrocarbons of heavy oil was very complex. The total ion chromatograms of saturated hydrocarbons collected on day 0 , day 2 , day 4 , day 6 and day 8 of consortium DL-1314 degradation were analyzed (Fig. S2). GC-MS analysis revealed approximately massive saturated hydrocarbons, which included C15-C35 n-alkanes, pristane (Pr) and phytane (Ph). In addition, unresolved complex mixtures were also detected. The abundance of C15-C35 n-alkanes, Pr, Ph and unresolved complex mixtures remarkably declined with time, indicating that the consortium DL-1314 significantly degraded saturated hydrocarbons.

The saturated hydrocarbons were rapidly degraded to $39.50 \%$ within 2 days when the easily biodegraded saturated hydrocarbons were used as carbon source for the consortium growth (Fig. 3). Then the biodegradation rate gradually declined with time. The degradation of the consortium DL-1314 lasted for 14 days and the maximum degradation efficiency of the saturated hydrocarbons was $66.32 \%$ on day 8 . The saturated hydrocarbons degradation process of consortium DL-1314 accords with the first-order reaction equation $\left(\mathrm{R}^{2}=0.99317, \operatorname{Ln} C=-0.1289 \mathrm{t}+6.2723\right)$, and the reaction rate constant is $0.1289 \mathrm{~d}^{-1}$, which is significantly higher than that of the heavy oil $\left(0.1123 \mathrm{~d}^{-1}\right)$, suggesting that saturated hydrocarbons enhanced the heavy oil
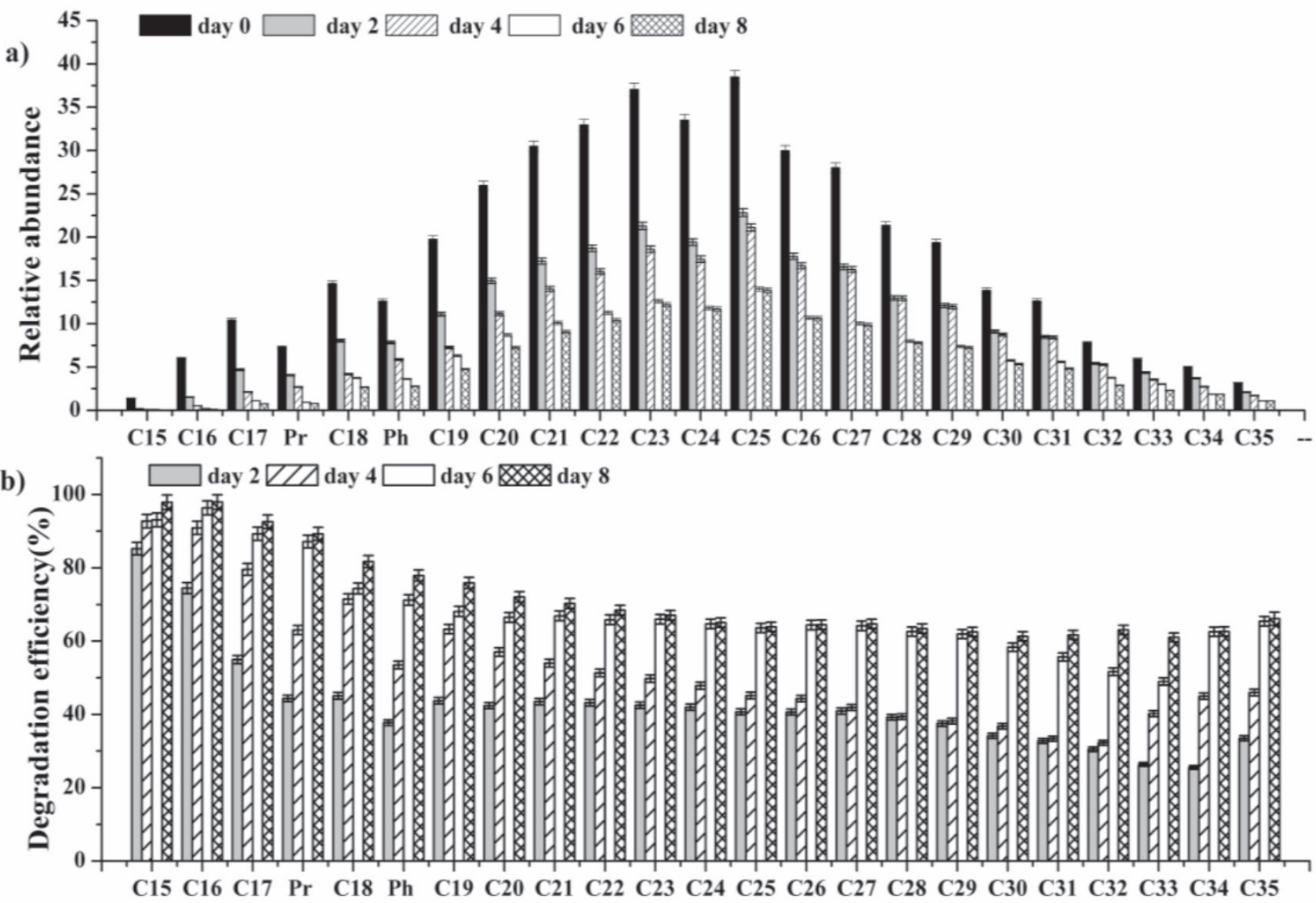

Fig. 4. Relative abundance a) and degradation efficiency b) of n-alkanes, $\mathrm{Pr}$ and $\mathrm{Ph}$. 
degradation. This phenomenon is also reported in the previous paper on crude oil degradation [18, 19].

The C19-C29 n-alkanes constituted a large proportion of the n-alkanes present in the heavy oil, indicating that the heavy oil was dominated by n-alkanes with higher relative molecular mass. C25 n-alkane was the dominant group of n-alkanes (Fig. 4a). For most of the saturated hydrocarbons, the consortium DL-1314 had a significant degradation effect. The removal efficiencies of saturated hydrocarbons decreased with increases in chain length. As shown in Fig. 4b), the consortium DL-1314 removed $92.57 \%-97.89 \%, 70.27 \%-81.69 \%$, and about $60 \%$ of C15-C17, C18-C21 and C22-C35, respectively.

$\mathrm{Pr}$ and $\mathrm{Ph}$ are usually regarded as biomarkers and have been used to study the geochemical properties of
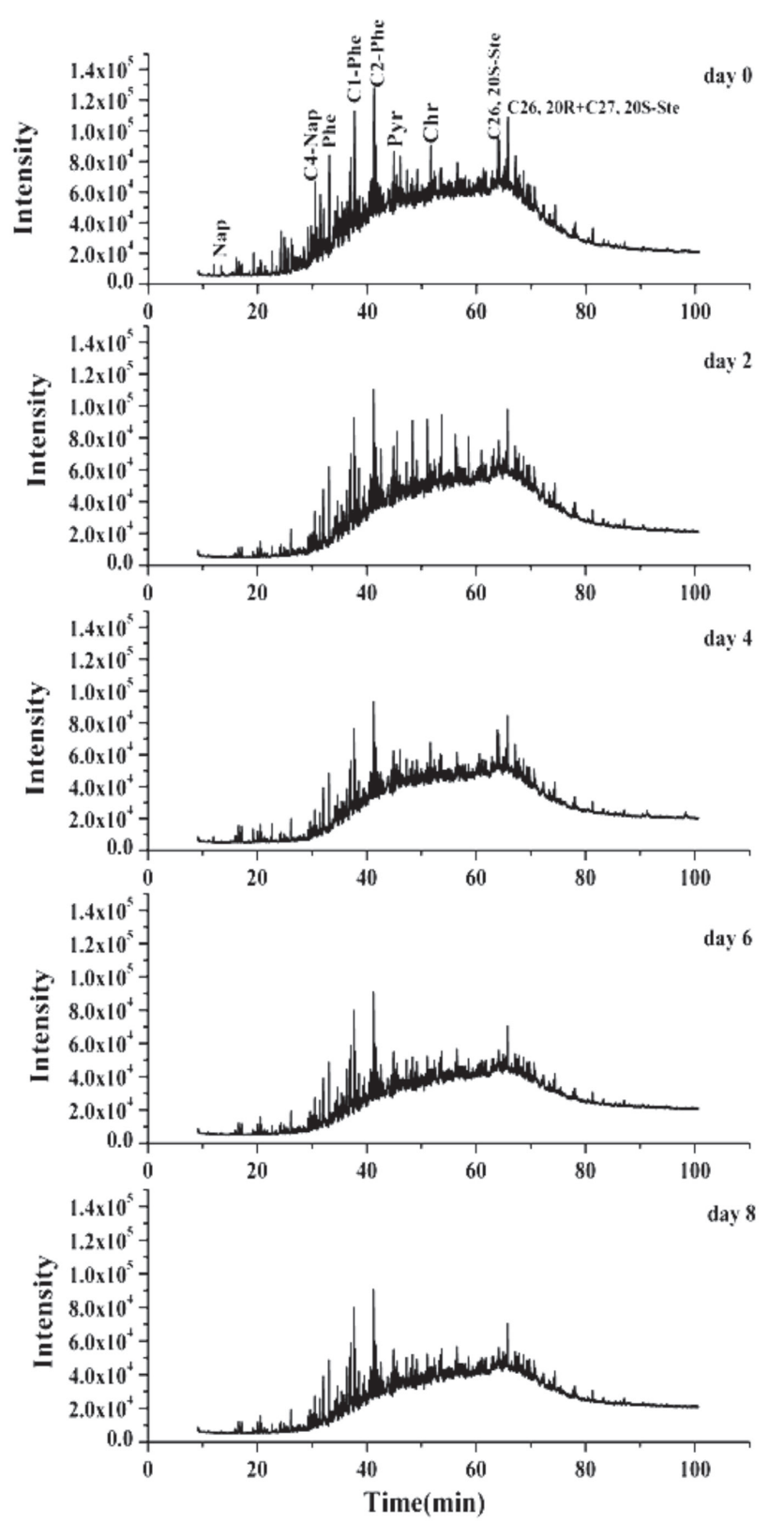

Fig. S3. Total ion chromatography of aromatic hydrocarbons. crude oil for decades due to their complex structures and stable chemistry [24]. Recently, these compounds, due to their high resistance to microbial degradation, have been proposed by environmental chemists for use in oil spills fingerprinting and as conserved markers for evaluating the degradation extent of spilled oil [25, 26]. Fig. 4b) also shows that the 8-day degradation efficiencies of $\mathrm{Pr}$ and $\mathrm{Ph}$ were $89.26 \%$ and $77.88 \%$, respectively, indicating that the consortium DL-1314 had higher saturated hydrocarbons degradation activity than the previously reported bacterial consortia [14, 27].

\section{Biodegradation of Aromatic Hydrocarbons of Heavy Oil}

The chemical composition of the aromatic hydrocarbons of heavy oil was very complex. The total ion chromatograms of aromatic hydrocarbons collected on day 0 , day 2 , day 4 , day 6 and day 8 of the consortium DL-1314 degradation were analyzed (Fig. S3). GC-MS analysis revealed approximately massive PAHs and biomarkers (sterane). In addition, the unresolved complex mixtures were also detected. Phenanthrene homologues (3-ring PAHs) were the dominant group of the aromatic fractions. Unsubstituted polycyclic aromatic compounds only constituted a small proportion of the heavy oil, while their alkyl derivatives constituted a much larger proportion (Fig. 6). This is consistent with the results of previous studies in which different types of crude oil $[28,29]$ and oil spill residues were characterized [30]. The abundance of aromatic hydrocarbons significantly declined with time, indicating that the consortium DL-1314 significantly degraded aromatic hydrocarbons.

The aromatic hydrocarbons were rapidly degraded to $43.36 \%$ within 2 days when the easily biodegraded hydrocarbons were used as carbon source for the consortium growth (Fig. 5). Then the biodegradation rate gradually declined with time. The degradation of the consortium DL-1314 lasted for 10 days and

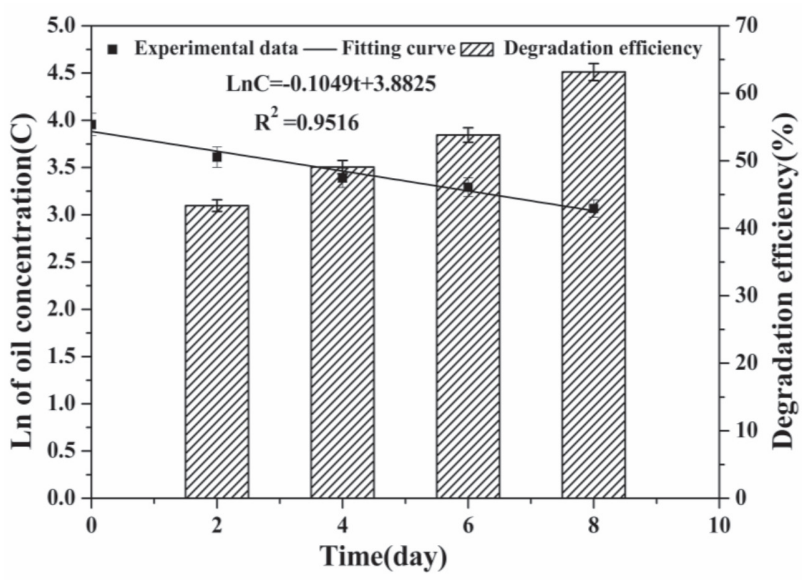

Fig. 5. Degradation efficiency and degradation kinetics of aromatic hydrocarbons. 


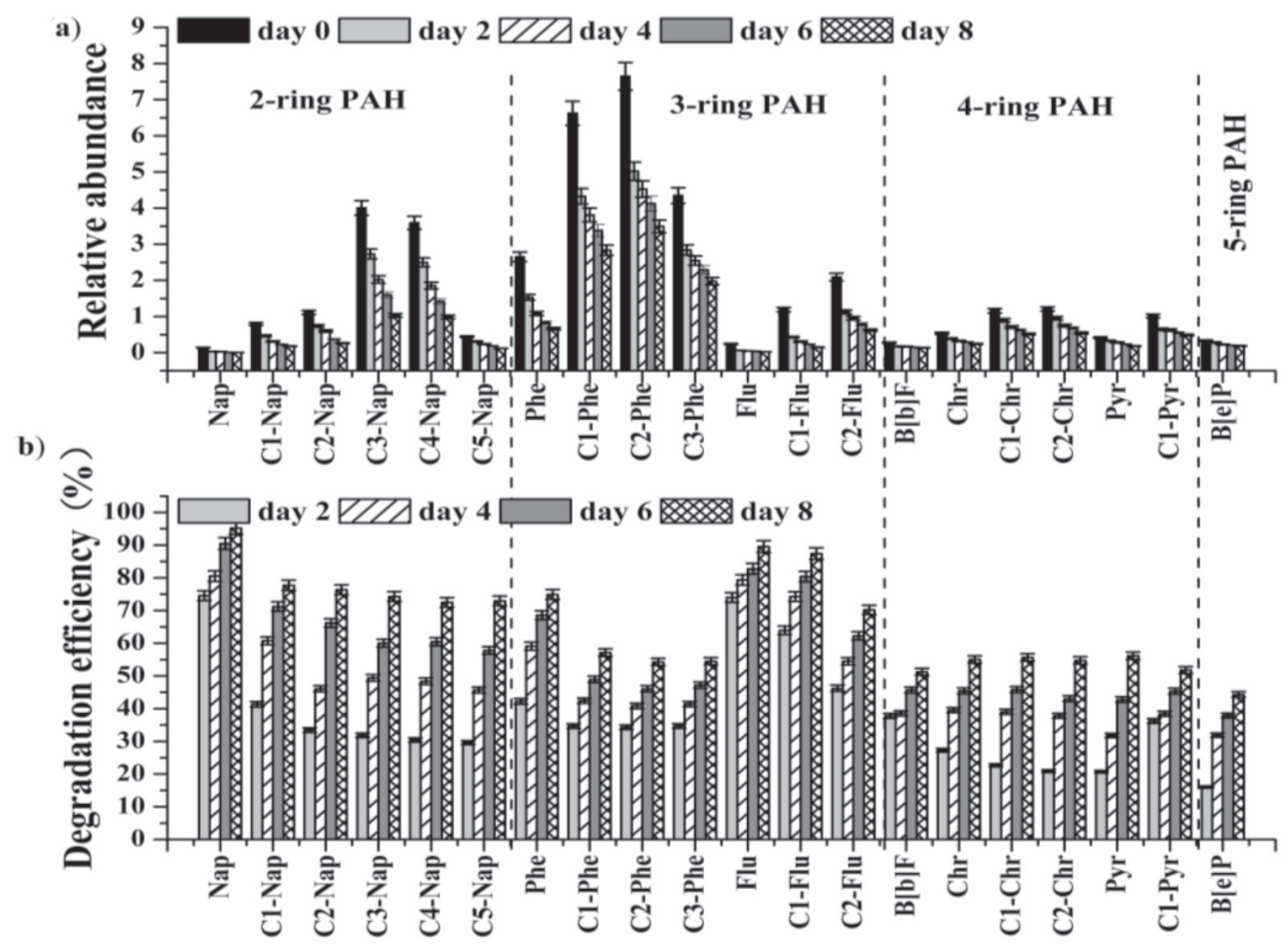

Fig. 6. Relative abundance a) and degradation efficiency b) of PAHs.

the maximum degradation efficiency of aromatic hydrocarbons was $63.16 \%$ on day 8 . The aromatic hydrocarbons degradation process of consortium DL-1314 accords with the first-order reaction equation $\left(\mathrm{R}^{2}=0.9576, \operatorname{Ln} C=-0.1049 t+3.8825\right)$, and the reaction rate constant is $0.1049 \mathrm{~d}^{-1}$, which is lower than the degradation processes of heavy oil $\left(0.1123 \mathrm{~d}^{-1}\right)$ and saturated hydrocarbons, indicating that aromatic hydrocarbons limited the heavy oil degradation.

The chemical composition of the PAHs of the heavy oil included naphthalene (Nap, 2-ring), phenanthrene (Phe, 3-ring), fluorene (Flu, 3-ring), chrysene (Chr, 4-ring), pyrene (Pyr, 4-ring), benzo[b]Fluorene (B[b] $\mathrm{F}$, 4-ring) and benzo[e]pyrene (B[e]P, 5-ring) (Fig. 6a). Un-substituted polycyclic aromatic compounds constituted a small proportion of heavy oil, while their alkyl derivatives constituted a much larger proportion (Fig. 6a). This is consistent with the results of previous studies [14, 27]. Phenanthrene homologues (3-ring PAHs) were the dominant group of the aromatic fraction. Fig. 6a also shows that the relative abundance of PAHs declined with time. After 8 days, the degradation efficiency of the detected PAHs was $63.16 \%$.

The removal efficiencies of PAHs decreased with increases in ring number. As shown in Fig. 6b), the consortium DL-1314 removed $72.97 \%-100 \%$, $54.30 \%-89.55 \%, 51.27 \%-56.19 \%$ and $44.32 \%$ of the 2-ring, 3-ring, 4-ring, and 5-ring PAHs, respectively. Statistical analysis revealed that significant negative correlations existed between the removal efficiencies of PAHs and the corresponding ring numbers. All of these data suggest that high molecular weight PAHs containing fused benzene rings were much more recalcitrant to biodegradation than the low molecular weight ones. The result is consistent with those of previous studies. PAHs containing fused aromatic rings have dense clouds of $\pi$-electrons surrounding them and stronger hydrophobicity, which contributes to the resistance of PAHs to microbial attack and degradation [31].

The removal efficiencies of PAHs decreased with increases in alkyl substitution degree. The degradation efficiencies of phenanthrene, C1-, C2and $\mathrm{C} 3$-phenanthrene, which are the dominant groups in PAHs, decreased by $74.91 \%, 57.16 \%, 54.52 \%$, and $50.30 \%$. A similar trend was found for most of the alkyl homologues of PAHs, such as naphthalene, fluorine and chrysene. PAHs with high degree alkyl substitution may inhibit the proper orientation of aromatic rings by dioxygenases [32].

\section{Dynamic Changes of Consortium DL-1314}

The composition of the consortium DL-1314 changed largely with the heavy oil degradation (Fig. 7). The initial composition of the consortium DL-1314 included 83.93\% DL-13, 10.71\% DL-34, and $5.36 \%$ DL-1, showing that the DL-13 was the dominant bacteria of consortium DL-1314. After 1 day, the relative content of DL-1 rapidly increased from 5.36\% to $89.33 \%$, indicating that DL-1 replaced DL-13 as the dominant bacteria of the consortium, meanwhile, 


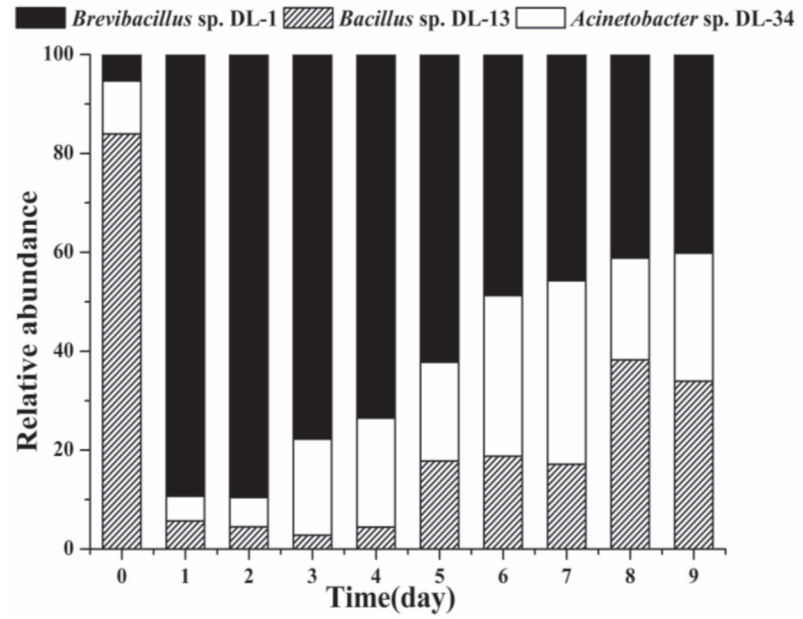

Fig. 7. Dynamic changes of consortium DL-1314.

the relative contents of DL-13 and DL-34 were 5.67\% and $5.0 \%$, respectively. Considering the experimental results presented in Table S2, DL-13 played a major role in the formation of surfactants in the early stage of degradation, and DL-1 had a clear advantage in the degradation of light components of heavy oil. The composition of the consortium DL-1314 remained essentially unchanged from day 1 to day 2 . Considering the degradation characteristics of heavy oil, the light hydrocarbons in heavy oil were completely degraded within 2 days. The relative content of DL-1 gradually decreased and the relative contents of DL-13 and DL-34 gradually increased with time. Thus, DL-13 and DL-34 have significant advantages in the degradation of refractory hydrocarbons. The result is consistent with previous studies [33, 34]. In addition, the dynamic changes of DL-13 and DL-34 were similar in the late stage of degradation. However, as presented in Table S2, compared with DL-34, DL-13 has a significant advantage in degrading heavy oil and its characteristic components. Thus, DL-34 and DL-13 can synergistically degrade refractory pollutants. This result further proves that Bacillus sp. DL-13 played an important role in heavy oil degradation. This result is consistent with that of 3.1. After 8 days, the composition of consortium DL-1314 was basically stable, and the total number of colonies significantly decreased (Fig. 1). The heavy oil degradation of the consortium entered the "stagnation period" [35] and the degradation reaction was inhibited by toxic hydrocarbons and metabolites.

\section{Conclusions}

In this study, a high efficiency heavy oil-degrading bacterial consortium DL-1314 was constructed using heavy oil degradation strains Brevibacillus sp. DL-1, Bacillus sp. DL-13 and Acinetobacter sp. DL-34. The consortium DL-1314 could degrade $60.75 \%$ of heavy oil with a reaction rate constant of $0.1289 \mathrm{~d}^{-1}$.
The degradation efficiencies of saturated hydrocarbons and aromatic hydrocarbons were $66.32 \%$ and $63.16 \%$, respectively, and aromatic hydrocarbons were the ratelimiting step for the consortium DL-1314 to degrade heavy oil. Bacillus sp. DL-13 and Brevibacillus sp. DL-1 played the important roles in producing surfactants and degrading the light hydrocarbons of heavy oil. Bacillus sp. DL-13 and Acinetobacter sp. DL-34 could synergistically degrade the refractory hydrocarbons. The results show that the consortium DL-1314 is a promising tool for remediating heavy oil-contaminated environments.

\section{Acknowledgements}

The work is financially supported by the National Key Research and Development Program of China (No. 2018YFC1801200, No. 2018YFC1801301).

\section{Conflict of Interest}

The authors declare no conflict of interest.

\section{References}

1. LLYIN S.O., ARININA M.P., POLYAKOVA M.Y., KULICHIKHIN V.G., MALKIN A.Y. Rheological comparison of light and heavy crude oils. Fuel. 186, 157, 2016.

2. GUO K., LI H.L., YU Z.X. In-situ heavy and extra-heavy oil recovery: a review. Fuel. 185, 886, 2016.

3. LEE E.H., KIM M., MOON Y.S., YIM U.H., HA S.Y., JEONG C.B., LEE J.S., JUNG J.H. Adverse effects and immune dysfunction in response to oral administration of weathered Iranian heavy crude oil in the rockfish Sebastes schlegeli. Aquat. Toxicol. 200, 127, 2018.

4. TAVASSOLI T., MOUSAVI M., SHOJAOSADATI A., SALEHIZADEH H. Asphaltene biodegradation using microorganisms isolated from oil samples. Fuel. 93, 142, 2011.

5. CHEN M., XU P., ZENG G.M., YANG C.P., HUANG D.L., ZHANG J.C. Bioremediation of soils contaminated with polycyclic aromatic hydrocarbons, petroleum, pesticides, chlorophenols and heavy metals by composting: applications, microbes and future research needs. Biotechnol. Adv. 33, 745, 2015.

6. WOLINSKA A., KUZNIAR A., SZAFRANEKNAKONIECZNA A., JASTRZEBSKA N., ROGUSKA E., STEPNIEWSKA Z. Biological activity of autochthonic bacterial community in oil-contaminated soil. Water Air Soil Poll. 227 (5), 130, 2016.

7. VARJANI S.J., UPASANI V.N. A new look on factors affecting microbial degradation of petroleum hydrocarbon pollutants. Int. Biodeter. Biodegr. 120, 71, 2017.

8. LIM M.W., LAU E.V., POH P.E. A comprehensive guide of remediation technologies for oil contaminated soil-Present works and future directions. Mar. Pollut. Bull. 109 (1), 14, 2016.

9. VARJANI J.S. Microbial degradation of petroleum hydrocarbons. Bioresource Technol. 223, 277, 2017. 
10. TENG Y., CHEN W. Soil microbiomes-a promising strategy for contaminated soil remediation: a review. Pedosphere. 29 (3), 283, 2019.

11. LI X.F., ZHAO L., ADAM M. Biodegradation of marine crude oil pollution using a salt-tolerant bacterial consortium isolated from Bohai Bay, China. Mar. Pollut. Bull. 105 (1), 43, 2016.

12. SARKAR P., ROY A., PAL S., MOHAPATRA B., KAZY S., MAITI K.M.K., SAR P. Enrichment and characterization of hydrocarbon-degrading bacteria from petroleum refinery waste as potent bioaugmentation agent for in situ bioremediation. Bioresource Technol. 242, 15, 2017.

13. WANG C.Y., LIU X., GUO J., LV Y.C., LI Y.W. Biodegradation of marine oil spill residues using aboriginal bacterial consortium based on Penglai 19-3 oil spill accident. China. Ecotox. Environ. Safe. 159, 20, 2018.

14. CAI B., MA J., YAN G.X., DAI X.L., LI M., GUO S.H. Comparison of phytoremediation, bioaugmentation and natural attenuation for remediating saline soil contaminated by heavy crude oil. Biochem. Eng. J. 112, 170, 2016.

15. DAS N., CHANDRAN P. Microbial degradation of petroleum hydrocarbon contaminants: an overview. Biotechnol. Res. Int. 2011, 1, 2011.

16. EBADI A., AZAM N., SIMA K., OLAMAEE M., HASHEMI M., NASRABADI R.G. Effective bioremediation of a petroleum-polluted saline soil by a surfactant-producing Pseudomonas aeruginosa consortium. J. Adv. Res. 8, 627, 2017.

17. XIA M.Q., FU D.F., CHAKRABORTY R., SINGH R.P., TERRY N. Enhanced crude oil depletion by constructed bacterial consortium comprising bioemulsifer producer and petroleum hydrocarbon degraders. Bioresource Technol. 282, 456, 2019.

18. YUAN X.Y., ZHANG X.Y., CHEN X.P., KONG D.W., LIU X.Y., SHEN S.Y. Synergistic degradation of crude oil by indigenous bacterial consortium and exogenous fungus Scedosporium boydii. Bioresource Technol. 264, 190, 2018.

19. KUMARI S., REGAR R.K., MANICKAM N. Improved polycyclic aromatic hydrocarbon degradation in a crude oil by individual and a consortium of bacteria. Bioresource Technol. 254, 174, 2018.

20. CHINA M.E.P. Water quality-determination of petroleum oil, animal and vegetable oils-infrared photometric method (HJ 637-2012). 2012

21. DAI X.L., YAN G.X., GUO S.H. Characterization of Dietzia cercidiphylli C-1 isolated from extra-heavy oil contaminated soil. RSC Adv. 7, 19486, 2017.

22. CHETTRI B., SINGH A.K. Kinetics of hydrocarbon degradation by a newly isolated heavy metal tolerant bacterium Novosphingobium panipatense P5:ABC. Bioresource Technol. 294, 122190, 2019.
23. KACHIENG'A L., MOMBA M.N.B. Kinetics of petroleum oil biodegradation by a consortium of three protozoan isolates (Aspidisca sp., Trachelophyllum sp. and Peranema sp.). Biotechnol. Rep. 15, 125, 2017.

24. LAN G.H., FAN Q., LIU Y.Q., LIU Y., LIU Y.C., YIN X.B., LUO M. Effects of the addition of waste cooking oil on heavy crude oil biodegradation and microbial enhanced oil recovery using Pseudomonas sp. SWP-4. Biochem. Eng. J. 103, 219, 2015.

25. WANG Z., FINGAS M.F. Development of oil hydrocarbon fingerprinting and identification techniques. Mar. Pollut. Bull. 47 (9-12), 423, 2003.

26. MODEL A.W., ANYIAM O.A., AMOBI J.O., NWEKE S.U. Gas chromatographic analysis of whole oil samples: implications for biodegradation in the Niger Delta. J. Petrol. Explor. Prod. Technol. 7, 89, 2017.

27. CHEN L.H., XIAO C.H., LUO X.F., SUN W.H. Study on biological degradation and transform characteristics of different components in petroleum hydrocarbon used by bacterial consortium. Environ. Earth Sci. 75, 815, 2016.

28. ATLAS R.M. Oil biodegradation and oil-degrading microbial populations in marsh sediments impacted by oil from the Deepwater Horizon Well. Environ. Sci. Technol. 49 (14), 8356, 2015.

29. STOGIANNIDIS E., LAANE R. Source characterization of polycyclic aromatic hydrocarbons by using their molecular indices: an overview of possibilities. Rev. Environ. Contam. T. 234, 49, 2015.

30. KANG H.J., LEE S.Y., ROH J.Y., YIM U.H., SHIM W.J., KWON J.H. Prediction of ecotoxicity of heavy crude oil: contribution of measured components. Environ. Sci. Technol. 48 (5), 2962, 2014.

31. LIANG L., SONG X., KONG J., SHEN C.H., HUANG T.W., HU Z. Anaerobic biodegradation of high-molecularweight polycyclic aromatic hydrocarbons by a facultative anaerobe Pseudomonas sp. JP1. Biodegradation. 25 (6), 825, 2014

32. BRAKSTADA O.G., RIBICICB D., WINKLERC A., NETZER R. Biodegradation of dispersed oil in seawater is not inhibited by a commercial oil spill dispersant. Mar. Pollut. Bull. 129, 555, 2018.

33. ZENG J., ZHU Q.H., WU Y.C., LIN X.G. Oxidation of polycyclic aromatic hydrocarbons using Bacillus subtilis CotA with high laccase activity and copper independence. Chemosphere. 148, 1, 2016.

34. ACER Ö., GÜVEN K., BEKLER F.M., GÜL-GÜVEN $\mathrm{R}$. Isolation and characterization of long-chain alkanedegrading Acinetobacter sp. BT1A from oil contaminated soil in Diyarbakır, in the Southeast of Turkey. Bioremediat. J. 20 (1), 80, 2015.

35. NOCENTINI M., PINELLI D., FAVA F. Bioremediation of a soil contaminated by hydrocarbon mixtures: the residual concentration problem. Chemosphere. 41 (8), 1115, 2000. 